\title{
Achieving digital inclusion of older adults through interest-driven curriculums
}

Jeanie Beh

Sonja Pedell

Bruno Mascitelli
Swinburne University of Technology, Australia

jebeh@swin.edu.au

Corresponding author.

Swinburne University of Technology, Australia spedell@swin.edu.au

Swinburne University of Technology, Australia bmascitelli@swin.edu.au

One outcome of increased life expectancy is that older adults are leading active lives in their third age as they seize opportunities to learn new skills, pursue new interests and hobbies to challenge themselves. However, there are many misconceptions about older adults' capabilities and aspirations, especially their attitudes towards technology. They are often misunderstood and seen to lack interest and motivation in the use of technology. Thus, this article examines interest-driven curriculums in order to achieve digital inclusion for older adults. Investigation methodology into this dilemma was best served with a mixed methods approach because, to date, there has been very little research about how technology could support older adults' interests. The majority of the existing studies consulted were focused on school children in a classroom setting. Older adults can differ greatly in their general background and level of technical experience and knowledge. Consequently, it would be very difficult to conduct quantitative research with control groups to investigate single variables. In compensation, 131 older adults, five staff members and eight teachers participated in this study. Qualitative methods such as observations and interviews (one-on-one and focus group) provided a deeper insight into teachers' experiences and teaching. Older adults were not always able to articulate their attitudes and problems with technology and consequently, observations were often a more effective

Beh, J., Pedell, S., Mascitelli, B. (2018). Achieving digital inclusion of older adults through interest-driven curriculums. The Journal of Community Informatics, 14(1), 60--81.

Date submitted: 2018-10-01. Date accepted: 2018-10-15.

Copyright (C), 2018 (the author as stated). Licensed under the Creative Commons AttributionNonCommercial-ShareAlike 2.5. Available at: www.ci-journal.net/index.php/ciej/article/view/1460 
means of data gathering. Finally, an Action Research approach was taken to trialling the concepts developed in the course of the investigation. This research comprised of four studies looked at expanding and extending on The Four-Phase Model of Interest Development by Hidi and Renninger (2006). The results show that when older adults are taught according to requests based on their preexisting interests, it encourages long-term engagement of technology and ability to integrate technology into their everyday lives, thereby achieving digital inclusion amongst older adults.

\section{Introduction}

In the three decades since Sir Timothy Berners-Lee invented the World Wide Web (WWW), the internet has changed our lives. There is an endless list of advantages that the internet is capable of providing for us. People across the globe are undertaking distance education, updating their social media profiles on Facebook, uploading video clips on YouTube, catching up on television programmes and keeping track of share and investment portfolios. There is an enormous supply of knowledge and information available through use of search engines like Google. We have cloud computing and cloud storage, providing us with a seemingly endless supply of storage space for backing up our precious data, such as our holidays snaps. Then, there is the Internet of Things (IOT) making home devices smarter and allowing them to be connected and access the internet. However, if individuals lack the basic technological skills then they will be excluded from accessing many of these digital services and information sources.

Back in 1965, E. A. Johnson invented the first finger-driven touch screen (Caprani, O'Connor \& Gurrin, 2012). Since then, there has been an evolution of touch screen technology. By the 1990s, we saw the launch of Apple's MessagePad 100 and Palm Pilot 1000. In 2006, Microsoft launched its Surface RT. Subsequently, Apple introduced its first generation iPad in 2010 and started selling them in large numbers. Then followed a series of different models and the latest is the iPad Pro. To date, it has sold more than 350 million units worldwide (Statistia, 2018). The reason for the popularity of touch screen tablets could be related to advantages that included ease of use, portability, speed, and ergonomic and lightweight design (Baker, Waycott, Pedell, Hoang \& Ozanne, 2016). These days, touch screen technology is ubiquitous (DanialSaad \& Chiari, 2017) and used from our homes, cars, offices, schools, restaurants, stores, museums, hotels, airports, aeroplanes, and any private and public spaces we can think of. They have become ubiquitous on devices such as our smartphones and tablets that we use every single day (Akhtar, Kemao \& Kakarala, 2017).

Another global trend happening in parallel to the rapid uptake of technologies in everyday daily life is the increased life expectancy of the population (DESA, 2015). This being about societal and economical challenges (Sander et al., 2015) but it also presents a new array of opportunities with more time available (Sanchez-Valle, Abad \& Llorenta-Barroso, 2017). As a matter of fact, people are living an average of 30 years longer now compared to the early nineteen century (ABS, 2017, n.p.). This means that 
we have a large segment of the populations whose needs need to be considered in regards to a more technology focussed life. The ageing population needs to be able to access services and stay in touch with their significant networks. Consequently, Senior IT classes are widely offered and the necessity to teach technology use to older adults stressed in literature (Beh, Pedell \& Doubé, 2015). However, such approaches have shown to be problematic as older adults might not see the relevance in attending such classes, feel that topics that are relevant for them are not addressed (Beh, Pedell \& Doubé, 2016) or taught in a way that learnings can be applied and retained. This research suggests that in order to support successful uptake of technology, existing interests need to be built upon. There has been very little research about how technology could support older adults' interests and vice versa how these interests could support the uptake of technology. This research is seeking to create awareness for older adults' needs, to address issues such as ageing and adoption of new technology. Results will inform future research in the use of mobile touch screen technologies by older adults, assisting organisations through curriculum development of life-long learning programs and investigation into future development of possible products and services. Thus, the authors examined how to achieve digital inclusion for older adults proposing an interest-based approach.

\section{Digital Economy Globally and in Australia}

Broadband internet brought about widespread changes in Information Technology (IT) and also had socio-economic impacts on the world. It led to globalisation, interconnectedness, easier communication, accessibility of information, on-demand services and manufacturing, improved productivity and performance of businesses and outsourcing (OECD, 2015). High-speed broadband and drastic reduction of costs for Information Communication Technologies (ICT) equipment continued to facilitate the rapid pace of the evolving digital economy (UNCTAD, 2017). Along the way, innovations influenced other sectors, for instance health, transport and government (Minges, 2016). The digital economy was providing opportunities for smaller businesses in developing countries to connect and grow (OECD, 2015). Two billion people were connected to the internet by 2017 and almost USD 8 trillion were exchanged through e-commerce (Manyika \& Roxburgh, 2011, p.1). An estimated 6.5\% of global GDP comes from the production of ICT goods and services (UNCTAD, 2017). In the ICT sector alone, almost 100 million people were employed (UNCTAD, 2017). In some countries, there were setbacks experienced in the 2007-09 global economic crisis but on the whole, the ICT sector was relatively resilient. E-commerce sales reached USD 25.3 trillion in 2015 (UNCTAD, 2017). By the end of 2017, there were 4.05 billion internet users around the world (IWS, 2018). Between 2010 and 2015, while the number of internet users grew by $60 \%$, nonetheless, more than half of the world's population remained offline (UNCTAD, 2017).

In Australia, internet subscriptions grew by 5.2\% from 32 million in June 2013 to 40.08 million in June 2017 (ACMA, 2016). This was largely attributed to the strong growth of fibre internet connections as part of the National Broadband Network (NBN) (COTA \& Jones, 2012). The internet is one of the tools that plays a very important role in 
everyday life. The internet enables us to communicate with family and friends, provides access to online courses, keeps us up to date with news and current affairs and facilitates global transactions of goods and services. Therefore, internet access is essential for older adults to take part in society. Internet penetration for Australia is $88 \%$ (Statista, 2018 n.p.), however, according to ABS (2017 n.p.), between 2016 and 2017, only $55 \%$ of Australians above the age of 65 years old and over are internet users. This is the lowest proportion of internet users compared to other groups such as teenagers and younger adults. Hence, there is a need to consider older adults and their access to internet.

\section{Mobile Touch Screen Devices}

The use of mobile touch screen devices is one of the options that could enable older adults to access the internet. Recently there has been much interest in Human-Computer Interaction (HCI) in researching the use of mobile touch screen devices for older adults (e.g. Pedell, Beh, Muzuno \& Duong, 2013; Waycott et al., 2012). Social inclusion would enable older adults to be connected with the world and to other people through the use of cutting edge technology. However, these studies focus more on tailoring solutions than the teaching of technology to older adults. This article argues that in order for older adults to avoid stigmatisation, they should learn the same technology as the rest of the population. One of the key aspects of successful ageing is for these adults to remain actively engaged in leisure activities (Nimrod, 2010). It has proven to be vital through fostering of social communications (Doyle, Skrba, Mcdonnell \& Arent, 2010). Technologies are also able to create new opportunities and stretch potential towards development of new activities for older adults (OECD, 2015). In addition, the quality of life for older adults has been enhanced through the use of technologies (Reeder, Zaslavksy, Wilamowska, Demiris \& Thompson, 2011) and simultaneously, enable them to remain connected in an inexpensive and flexible way (Satariano, Scharlach \& Lindeman, 2014). Moreover, mobile touch screen devices can be easier to use than some equivalent technologies as they accommodate some of the age-related physical and cognitive limitations faced by older adults (Upton, Upton, Jones, Jutlia \& Brookder, 2011; Caprani et al., 2011). The close proximity of keyboard to information on the screen could increase spatial contiguity and reduce cognitive load (Doubé \& Beh, 2012). In addition, mobile touch screen devices enable items such as buttons and texts to be enlarged, making them (a) easier to see, and (b) easier to select accurately (Caprani et al., 2011).

\section{Human Lifespan and Ageing}

Although, the human lifespan is usually determined by chronological age (Lindsay Jackson, Schofield \& Olivier, 2008) and usually associated with events such as graduation, marriage and retirement as a form of lifespan measurement, no two individuals will live exactly the same life. Therefore, Kendig and Browning (2011) argue that ageing should be described as a transition and that the older members of the population should not be segregated (Durick, Robertson, Brereton, Vetere \& Nansen, 2013). This is because we are all going to age (Agronin, 2011) and no one can escape 
the ageing process unless they die young (Whitbourne, 2008). The stereotypical perspective of older adults as being in poor health, as living in isolation, as lacking sharpness of mind, as not capable to use and/or learn technology and as being unproductive has changed over time (Edgar, 2013). People identified in the older adult age group rarely perceive themselves as being old, if they are still living independently, remaining autonomous and are leading active lives (Durick et al, 2013). The majority of older adults remain alert, aware, healthy, active and involved with their local communities (Betts, 2014). According to Sperry and Prosen (1996), the stereotype of ageing should not be justified on general decline in cognitive and physical functions. Slowing down is not equivalent to being incompetent (Saxon, Etten \& Perkins, 2015). Older adults are as capable of contributing their knowledge and experiences to their communities as their younger counterparts (Harvey \& Thurnwald, 2009). Therefore, it is imperative for older adults to remain active and engaged in their lives, as staying active mirrors interest in the aspiration and motivation to continue with learning (Östlund, 2005), that includes technology (Durick et al., 2013).

\section{Technology and Ageing}

Generally, technologies were not built with older adults in mind. The main drivers in the advancement of technology usually occur as a result of economic or military influences. The shift in technology changes as society progresses. The impact of technological change has led to the creation of new processes and products, increased efficiency and lower costs, and facilitation of the evolution of economies (Wheale \& Amin, 2010), for instance the stock market and e-commerce. The dot com bubble occurred between 1995 and 2000 (Morris \& Alam, 2012). During this timeframe, there was an exponential growth in the adaptation and usage of the internet by businesses and consumers. Despite the bursting of the bubble, one consequence was the advancement in technology enabling people to harness its potential to create social impact (Berzin, Singer \& Chan., 2015). Societal change was at times slow as it would wait for technology to progress. As people are living longer and thus focusing on their quality of life, they also want to be able to continue to learn new skills and be engaged through their third age. The widespread availability of mobile touch screen devices has reduced the economic barriers for most people living in developed countries. As they continue to become more affordable, there is a shift in the way older adults are able to communicate with friends and families, thus reducing their level of social isolation. Even though technology might be able to dissipate the digital divide amongst older adults, their limitation of knowledge and exposure to technology means that older adults are often being left behind. Although, there are technology courses and classes accessible via local community centres and houses that are offered to older adults at affordable rates, they often follow a one-fits-all approach. The curricula are often put together by teachers and cover what they consider to be relevant not considering that older adults have different technology needs in terms of communication, do not need to apply technologies for work practices and are a very inhomogeneous group even though they might be of similar age. Interests differ widely depending on previous experiences, cultural background and perceptions of purposeful use of technology. Nonetheless, there is 
limited education and resources available to facilitate older adults' uptake of mobile touch screen devices approaching from the perspective of their pre-existing interests.

\section{Theoretical Framework}

\section{The Four-Phase Model of Interest Development}

The four-phase model of interest development developed by Hidi and Renninger (2006) was illustrated and adopted for this study (see Figure 1). It extends and expands on their earlier three-phase model published in 2002 (Krapp). The four-phase model of interest development consists of the following: (a) phase one - triggered situational interest, (b) phase two - maintained situational interest, (c) phase three - emerging individual interest, and (d) phase four - well-developed individual interest.
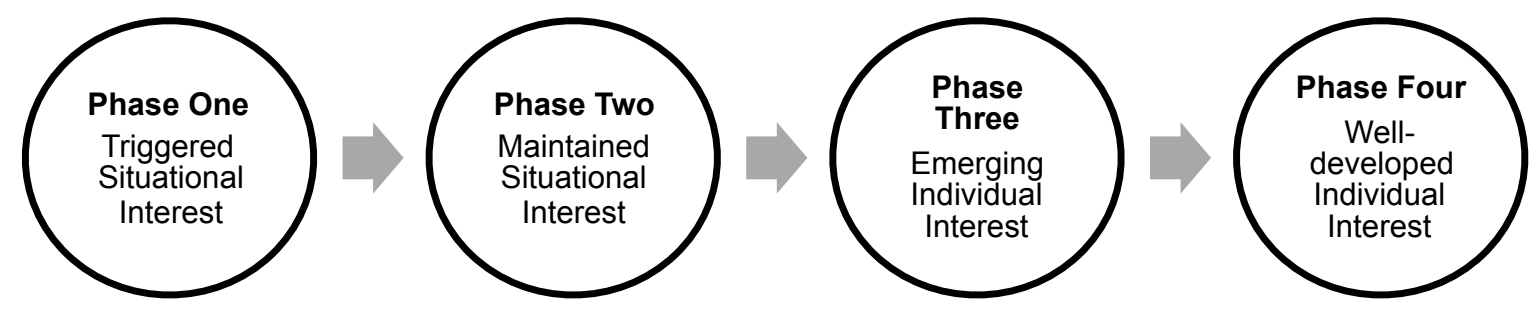

Figure 1: The Four-Phase Model of Interest Development by Hidi and Renninger

(2006).

Renninger \& Hidi (2011) have suggested that triggered situational interest could be sparked by either environmental or textural features, as a psychological state resulting from short-term changes in both affective and cognitive processing. Maintained situational interest is described as subsequent to a triggered state. It typically occurs over an extended period of time, reoccurs persistently and involves focused attention (Renninger \& Hidi, 2011). In maintained situational interest, learners are drawn to understand more about particular content, and are inclined to ask questions about it, thus marking a shift in phases of interest (Renninger \& Su, 2011). Emerging individual interest refers to the beginning phases of an enduring predisposition indicated by seeking repeated engagement with particular content over time. Well-developed individual interest is defined as showing a relatively enduring predisposition toward engaging with the particular content over time (Hidi \& Renninger, 2006). Renninger and $\mathrm{Su}$ report that "learners at all ages with varying experiences can develop new interest at any time but age also affected how and whether interest is likely to develop" (2011, p. 171). Related to this research, the authors propose here that it is important to know about existing interests of older adults in order to leverage them in technology learning. As a first step it is important to better understand the relationship between individual interest and technology uptake by older adults. This is partly because the model of the four-phase model of interest development suggested by Hidi and Renninger (2006) neither focuses on older adults nor on technology learning. 


\section{Self-Determination Theory (SDT)}

Numerous studies related to SDT were conducted for children, adolescents and younger adults. In high schools, studies included practical subjects such as physical education (Standage, Duda \& Ntoumanis, 2005) and within the higher education sector (e.g., universities), subjects such as organic chemistry (e.g. Black \& Deci, 2000), second languages (Noels, Pelletier, Clement \& Vallerand, 2000), law (Sheldon and Krieger, 2007) and medicine (Williams and Deci, 1996). SDT studies have also been conducted in different sectors, for instance corporate (e.g. Deci, Olafsen \& Ryan, 2017) and charity organisations (e.g. Deckop \& Cirka, 2000). According to Ryan and Deci,

although motivation is often treated as a singular construct, even superficial reflection suggests that people are moved to act by very different types of factors, with highly varied experiences and consequences. People can be motivated because they value an activity or because there is strong external coercion. (2000, p. 69)

Self-Determination Theory (SDT) distinguishes several types and levels of human motivation within a framework of goals (Niemiec \& Ryan, 2009). Deci and Ryan (1985) define the three important elements that make up SDT to be: (a) autonomy, (b) competence, and (c) relatedness (see Figure 2).

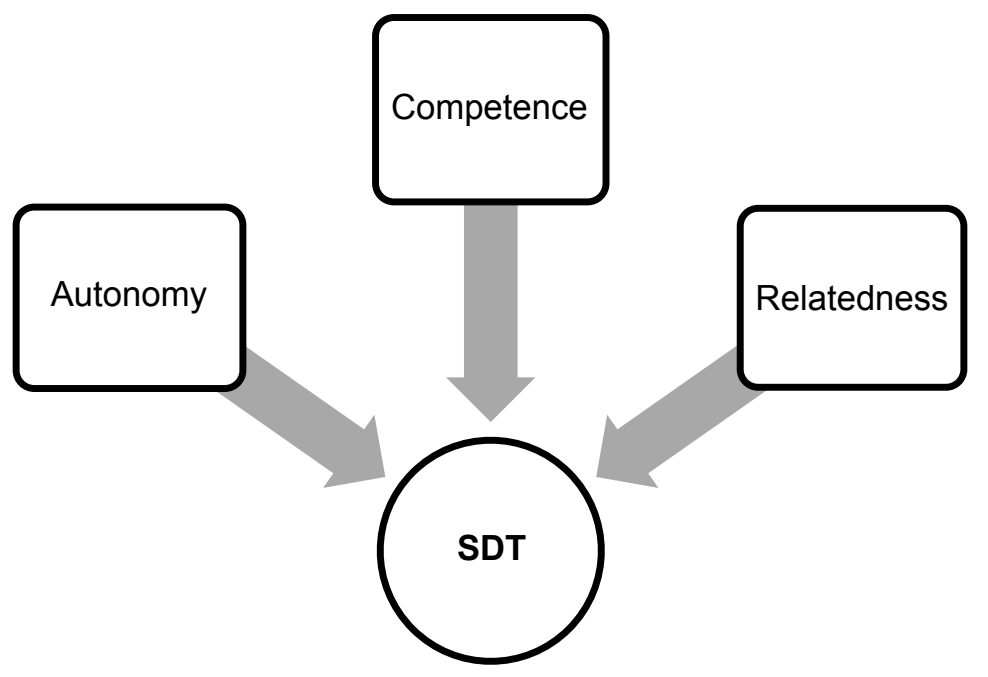

Figure 2: Self-Determination Theory (SDT) by Deci and Ryan (1985).

These three elements are the essential foundation of the development of personal wellbeing and social development (Ryan and Deci, 2000). Both autonomy and competence are classified as basic psychological needs and necessary for sustained motivation (Niemiec and Ryan, 2009). Sound learning outcomes are more likely if determined by individuals who feel that they have a certain amount of control over their learning (Hagay et al., 2013). Motivation can be classified along a continuum from intrinsic to extrinsic (Reeve, 2005). Deci and Ryan (2008) report that the latter theory was indeed a stable idea due to the abundance of research. Since the mid-1980s, Deci and Ryan (1985) have been leaders in motivational research in education. In this research it was 
intended that this theory would act as a framework in focusing on older adults' learning and uptake of technology.

\section{Socioemotional Selectivity Theory (SST)}

There has been little research conducted towards older adults with use of the SelfDetermination Theory (SDT). Whereas, in contrast, Socioemotional Selectivity Theory (SST) is of relevance to older adults. Mainly because SST is also known as life-span theory of motivation, this theory maintains that as people start to age, they realised that their time horizons shrink (Carstensen, 1992). SST was developed by Carstensen, an American psychologist (1992). In SST, time remaining is viewed as a constraint. Older adults become very aware that there is limited time. Perception of time plays a vital role in the decision making towards the selection and pursuit of individual goals (Carstensen, Isaacowitz \& Charles, 1999). Therefore, older adults tend to be more selective about making the right choices so as not to waste their precious time. Carstensen et al. (1999) claim that SST plays an important role; it determines the motivational shift leading older adults' to invest their time to select and pursue goals and activities that are emotionally meaningful (Charles \& Carstensen, 2009; Carstensen $\&$ Charles, 1998). Charles and Carstensen (2009) state that ageing brings changes to social and emotional life. Besides motivational shifts, ageing also influences personal goals. Studies show that younger adults perceive their future as open-ended and therefore they prioritise their goals towards knowledge-related goals. They concentrate on acquisition of knowledge in order to plan for endeavours that would pay off in the future such as getting a job promotion. On the other hand, older adults shift their focus towards emotion-related goals directing their attention towards goal-relevant information to deepen existing relationships and fulfil personal satisfaction (Carstensen, 2007) (see Figure 3).

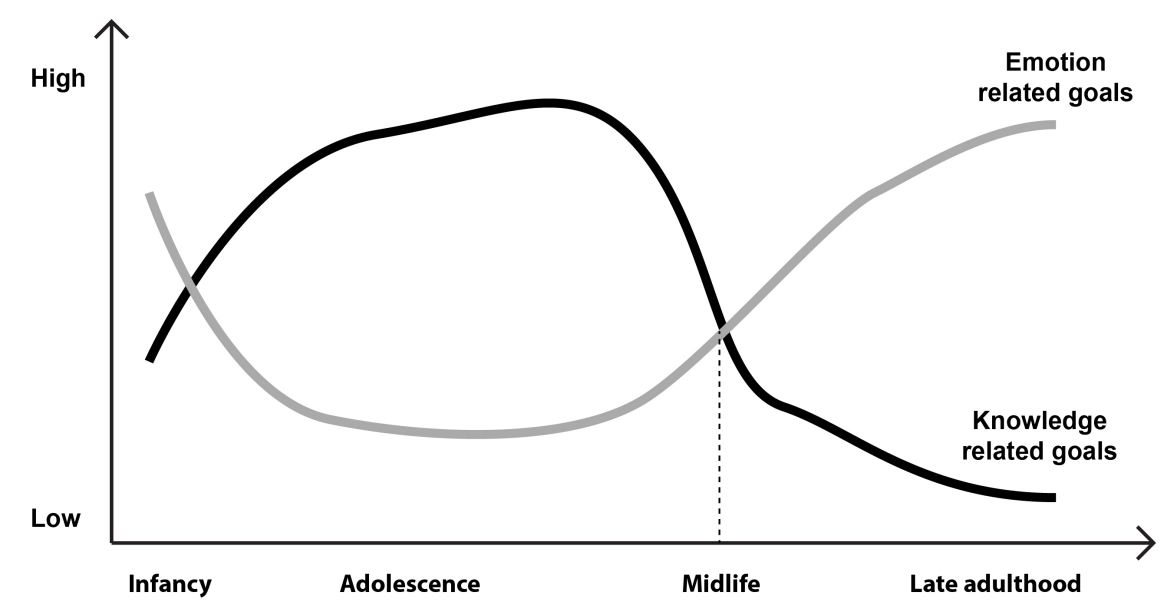

Figure 3: Socioemotional Selectivity Theory (SST) by Carstensen (1992).

A number of studies (i.e. Wilson, Scherr, Schneider, Tang \& Bennett, 2007; Barnes, Mendes de Leon, Wilson, Bienias \& Evans, 2004) show that older adults with strong social connections are less likely to experience decline in their cognitive functioning. Social networks also contribute towards regaining higher cognitive functioning 
(Glymour, Weuve, Fay, Glass \& Berkman, 2008). Therefore, suggesting that older adults might be able to learn technology, in particular, touch screens, when they are attending classes with other like-minded individuals.

\section{The Study: Interest-based Classes}

Studies were conducted to create an interest framework combining these theoretical concepts specifically for older adults and their uptake of technology with associated teaching methods. The framework was trialled in practice with teaching methods. 131 older adults, five staff members and eight teachers were involved in total, across the four studies.

\section{Methodology}

The methodological approach used in the fieldwork explored the theoretical framework on interest by Hidi and Renninger (2006), Self-Determination Theory (Deci \& Ryan, 1985) and Socioemotional Selectivity Theory (Carstensen, 1992). To date, there has been very little research about how technology could support older adults' pre-existing interests (Boulton-Lewis, 2009) and it is a very complex topic with many variables influencing the learning and adoption of technologies. Therefore, the authors made the assumption that investigation of the research questions of this study was best served with a range of qualitative and quantitative approaches (Patton, 2015). The methodology comprised of in-depth and focus group interviews (qualitative). The latter consisted of background demographics and pre-, mid- and post-study questionnaires (quantitative).

\section{Exploratory Study}

There were 32 participants -24 women and eight men. Participants were all above 65 years old with most in their $70 \mathrm{~s}$ and $80 \mathrm{~s}$. None of the participants had grown up with technology. Other challenges included illiteracy and problems in speaking English (Italian participants). Only one participant owned an iPad, which was given to her by her daughter as a gift. The rest had heard of iPads, but had no experience in using them. The study of this activity group was carried out over a period of 12 weeks. The duration of each weekly visit was two hours. It led to video and audio recordings of group interactions (including focus group, observations and journaling). Two interviews were conducted with staff members. Based on findings from the Exploratory Study, the majority of older adults; approximately $97 \%$ in this activity group had not been exposed previously to technology in general. Therefore, their interest in technology was not triggered till mobile touch screen technology was introduced by the researchers. The most frequently encountered pre-existing interests (Table 1) included games such as crossword puzzles, Scrabble, Sudoku, Bingo, Solitaire, Ludo, Monopoly and jigsaw puzzles. Other pre-existing interests also consisted of drawing, music (listening and playing instruments), cooking, gardening, football, knitting and crafts. These activities were matched to equivalent apps on the iPad by researchers (Table 2). Participants were also comparing the differences between reading a physical copy of newspapers and a 
softcopy on the iPad. With the latter option, it enabled participants to enjoy multimedia content, such as video clips, and also the iPad provided them with flexibility to enlarge font sizes to suit individual reading preferences. Based on observations of duration of involvement, degree of social interaction, facial expressions, questions, and tone of voice, the most engaging apps appeared to be Google Earth to initiate conversations about home countries and general knowledge, musical instruments, for instance Tiny Piano and competitive games such as Fruit Ninja and Air Hockey (Figure 4). Consequently, the researchers had put forward an initial phase of no interest to be extended onto Hidi and Renninger's four-phase model of interest development to cater for older adults in similar situations. This extended model will be employed by the researchers in the next study.

Table 1: Most common pre-existing interests of participants derived from focus group interviews.

\begin{tabular}{|c|c|}
\hline \multicolumn{2}{|c|}{ Pre-existing Interests } \\
\hline Crossword puzzles & Ludo \\
\hline Drawing & Playing musical instruments \\
\hline Scrabble & Monopoly \\
\hline Sudoku & Jigsaw puzzles \\
\hline Listening to music & Family history \\
\hline Bingo & Cooking \\
\hline Solitaire & Gardening \\
\hline Football (Aussie Rules) & Knitting \\
\hline Crafts & Watching television \\
\hline
\end{tabular}
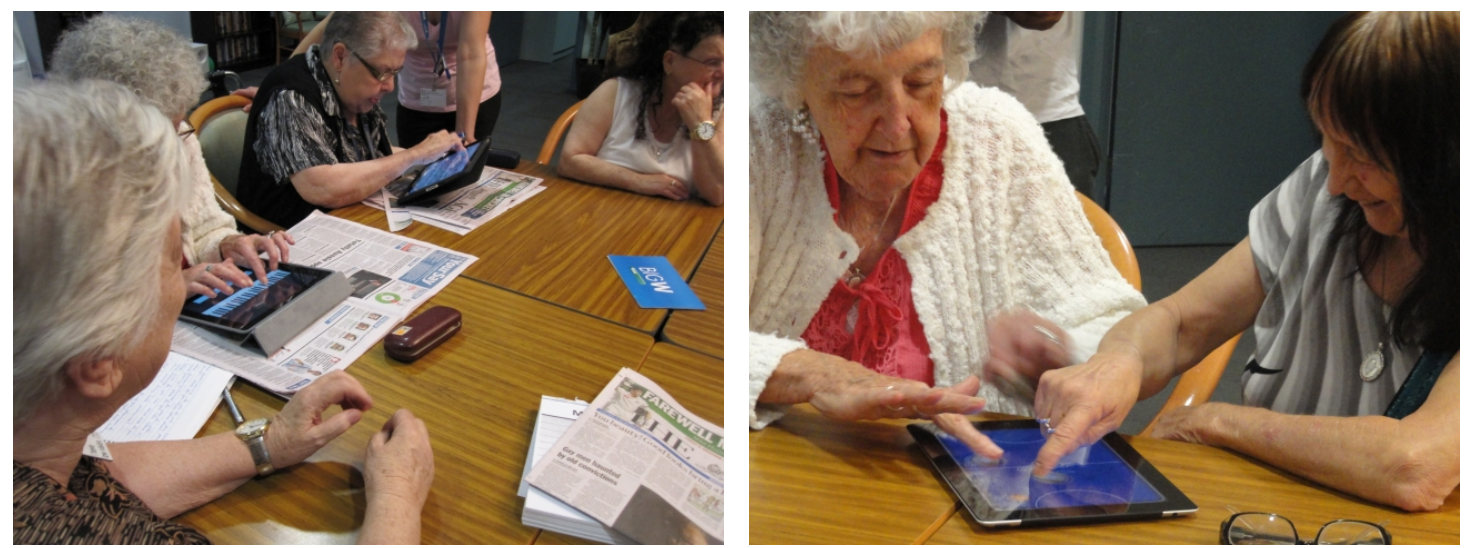

Figure 4: Participants interacting with iPads. 
Table 2: Most common pre-existing interests and pairing of suggested equivalent apps were matched by researchers.

\begin{tabular}{|c|c|}
\hline Pre-existing Interests & Equivalent Apps \\
\hline Drawing & Sketchbook Pro \\
\hline Reading newspapers & The Age, Herald Sun \\
\hline Watching television & YouTube, ABC iView \\
\hline Listening to music & ABC radio \\
\hline Playing musical instruments & Tiny Piano, Drum Kit, Ukulele \\
\hline Gardening & ABC Gardening Australia, Flower Garden \\
\hline Word puzzles & 4 Pics 1 Word \\
\hline Football (Aussie Rules) & AFL Footy Live \\
\hline Playing games & $\begin{array}{l}\text { Fruit Ninja, Tic Tac Toe, Ludo. Air Hockey, } \\
\text { Monopoly, Bingo, Solitaire, Jigsaw Puzzles }\end{array}$ \\
\hline Family history & Google Earth \\
\hline
\end{tabular}

\section{Comparative Study}

Four different approaches were compared, in terms of teaching focusing on differing levels of interest and engaging 35 older adults, both with and without technology, in order to explore their uptake of mobile touch screen technologies. The Comparative Study took place over a twelve-week period. With weekly visits of about eight hours across four activity classes. The study involved two hours weekly for each activity class. These visits led to recordings of group interactions that comprised of focus group interviews, observations, journaling and questionnaires with participants from their respective classes. In order to investigate the relationship between technology uptake and pre-existing interests more systematically several activity classes with varying level of interests and technology use were compared. These four activity classes were chosen based on the four conditions relevant to compare in regards to: (a) iPad Classes interest in technology, (b) computer classes - interest in technology, (c) water-colour painting with iPad classes - interest in technology and pre-existing interest, and (d) water-colour painting - pre-existing interest. In this instance, both technology classes (iPad and computer) had the same condition of interest in technology because the researchers were exploring and comparing the uptake of two different technologies and older adults' pre-existing interests. In addition, it has been confirmed that mobile touch screen tablets appear to be a technology that is relatively easy to understand and use for older adults.

The study has recognised the importance of structuring a curriculum that catered towards older adults' pre-existing interests in order to facilitate their learning of technology. Self-motivation was a pivotal factor that contributed to the success of the Water-colour Painting Classes for older adults that participated. Self-motivation was mentioned in interviews by teachers from the Exploratory Study and researchers' 
observations of participants and these were further supported by results of participants' attitude scales towards technology. After some scrutiny of existing approaches, the study found that "self-motivation" embodied in the second existing theory SelfDetermination Theory (SDT) by Deci and Ryan (1985) most corresponded to the conditions of this study. This theory comprises of three elements: (a) autonomy, (b) competence and (c) relatedness (Figure 3). According to Reeve (2005) (Table 3), autonomy represents listening and allowing others to work in their own individual way, while nurturing their inner motivational resources and thus promoting valuing. Competence is believed to increase over time, thus providing optimal challenges, skillbuilding, encouragement, and tips and hints for progress to take place. Relatedness enables individuals to express affection, liking and appreciation. It then leads to sharing of personal resources such as time, attention, energy, interest and other emotional support. These three elements are summarised in (Figure 5).

Table 3. Elements and summary of SDT for older adults.

\begin{tabular}{|c|l|}
\hline Elements & \multicolumn{1}{c|}{ Explanations } \\
\hline Autonomy & $\begin{array}{l}\text { Listens and allows others to work in their own individual way } \\
\text { Nurtures inner motivational resources } \\
\text { Promotes valuing }\end{array}$ \\
\hline Self-confidence & $\begin{array}{l}\text { Feeling of being respected, valued as an individual and being part } \\
\text { of the community }\end{array}$ \\
\hline Life-satisfaction & $\begin{array}{l}\text { Fulfil purposes, using and share of interest, existing knowledge, life } \\
\text { experiences and providing peer-support }\end{array}$ \\
\hline
\end{tabular}

Source: Reeve, 2005 and Beh et al., 2015.

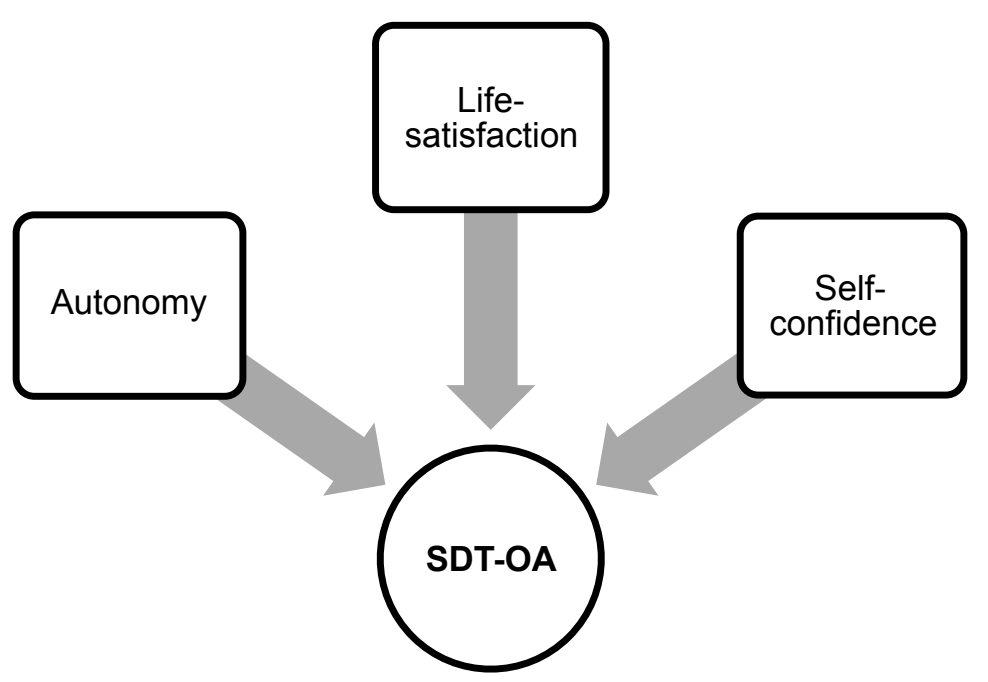

Figure 5. Elements for Self-Determination Theory for Older Adults. 


\section{Conceptual Phase}

In order for the study to develop a better understanding as to whether the efforts to extend on the Interest-Bridge Model would increase the uptake of technology amongst older adults, an environment was required to trial and translate the theory that was developed into practical guidelines and tools. In order to do so, a pilot class was organised to trial and assess the efficiency of the suggested teaching tools. The guidelines (see Table 4) were supported by themes stemmed from interviews with seven teachers conducted as part of this research (not reported here - please refer to Beh et al., 2016), and motivational theories from SDT and SST. These are crucial requirements to facilitate with the running of technology classes for older adults.

Table 4. Guidelines developed for running of classes.

\begin{tabular}{|c|c|c|}
\hline Life-satisfaction & Autonomy & Self-confidence \\
\hline Purposes & Own devices & Handing out materials \\
\hline Goals & Decisions on curriculum & Repetitions \\
\hline Pre-existing interests & --- & Self-directed use at home \\
\hline
\end{tabular}

In the Conceptual Phase, the concept trialled in this study comprised of the InterestBridge Model, background demographics, pre-, mid- and post-study questionnaires, card-sorting exercises and guidelines for running of classes for older adults (Table 5). The concept and tools developed were refined after the Conceptual Phase and will be employed in the next study.

Table 5. Tools developed in the Conceptual Phase.

\begin{tabular}{|c|l|}
\hline \multicolumn{2}{|c|}{ Tools Developed in the Conceptual Phase } \\
\hline 1. & Interest-Bridge Model \\
\hline 2. & Background demographics \\
\hline 3. & Pre, mid and post-study questionnaires \\
\hline 4. & Card-sorting exercises \\
\hline 5. & Guidelines for running classes \\
\hline
\end{tabular}

\section{In-Depth Study}

The overview of the study (Figure 6) began through seeking participants' pre-existing interests via background demographics. This took place before the commencement of individual classes. These pre-existing interests provided by participants were not related to technology. Additionally, participants were asked to provide the current technological barriers they faced and their technological experiences, with the intention of finding out the factors affecting their learning. The assumption was based on knowledge and confidence being the two main factors affecting older adults' uptake of technology. The materials handed out during classes and the basic knowledge taught in classes were 
influenced by the two factors mentioned above. Correspondingly, ad-hoc teaching took place in classes and these activities were based on participants' requests. These activities were completely new requests thus instead of resolving the current technological barriers faced by participants, new technological barriers were uncovered. Subsequently, these barriers could be managed through the repetitions of activities during classes. Therefore, these formed the basis of the conceptual model for the running of classes.
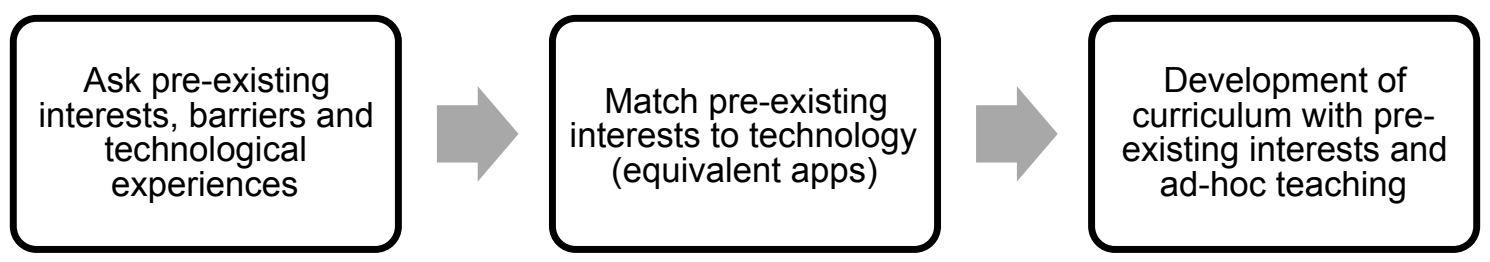

Figure 6: Overview of the study.

The tailoring of contents has led to very different contents taught between these groups (ten in total), while, some of the contents taught were more popular than others (Table 6). The classes ran were, to a certain extent, ad-hoc based. Participants suggested completely new requests. For example, from basic activities such as creating and deleting folders to more advanced activities, for instance transferring of photographs between devices and backing up data.

Table 6: Activities requested by participants to be taught based on individual groups.

\begin{tabular}{|c|c|}
\hline Group & Activities Requested \\
\hline 1 & Skype, FaceTime, emails, sync with other devices (smartphones and laptops) \\
\hline 2 & Camera, video camera, camera roll, photo transfers, photo stream, delete photos \\
\hline 3 & Downloading photographs from emails attachments, contact lists, photo transfers \\
\hline 4 & iCloud, e-books, newspapers, email attachments, organise photos \\
\hline 5 & E-books, newspapers, backing up of data, YouTube, iCloud, email \\
\hline 6 & Organise photos, online banking, share portfolio, online shopping, ad-blocks \\
\hline 7 & iCloud, backing up of data, calendar, online shopping, updating of operating system \\
\hline 8 & Bookmarks (web pages), iCloud, online shopping, backing up of data, podcast \\
\hline 9 & E-books, pay bills, online shopping, Microsoft Word, search history, iCloud \\
\hline 10 & Camera, camera roll, photo transfers, photo stream, Facebook, printing \\
\hline
\end{tabular}

For example, the majority of the participants from group one had children and relations living overseas, therefore their requests were to learn more about communication apps, such as Skype and FaceTime, in order to stay in touch with their family and friends. Due to the different time zones, most participants try to keep in touch with their children and relations through emails. Participants from group two requested to learn about photography, which included the use of still camera and video camera and photo gallery. Participants were also interested to acquire skills such as transferring of 
photographs from their mobile touch screen tablets to desktop computers and/or laptops as backups. They also requested to learn about sorting of photographs such as creating folders, renaming folders and categorising. Some of the participants were committee members of U3As. As their roles include organising meetings and allocating spaces for courses, therefore they requested to learn about Microsoft Word in order to keep track of meeting minutes and to create newsletters for other members. The researchers went through with the participants the basic functionalities such as font type, font size, font colour, alignment, inserting images and saving documents.

\section{Feedback from Participants about Classes}

Based on the feedback provided by participants, classes have been a success. There was a consensus from a large number of participants in written feedback. They confirmed that they had enjoyed the classes and had increased their knowledge of mobile touch screen technology use. Success of these classes is illuminated from the feedback provided by the participants when teaching through participants' requests based on their pre-existing interests:

[Tutor] was most obliging in covering everything that we expressed interest in. Participant 38.

The benefits of the classes are due to the expertise of the tutor, offered new approaches to the iPad learning. - Participant 19

Thank you for your enthusiasm and willingness to impart your knowledge in answering our questions and following our interests. [...] very useful for travel. But I was starting from base - I didn't even own tablet when I started. [...] it has stimulated me to purchase an iPad. - Participant 5

\section{Reflecting on Conceptual and Theoretical Framework}

This study has adopted Hidi and Renninger's four-phase model of interest development for older adults and their learning of mobile touch screen technologies based on their pre-existing interests. However, findings from the Exploratory Study indicated the need to expand on the model because participants did not have prior technological skills and were introduced to a new form of technology: mobile touch screen devices. Hence, they were not in the Triggered Situational Interest phase and therefore, a No Interest phase was added into the model. In the Comparative Study, findings suggested that the current interest model could facilitate older adults with their learning of mobile touch screen technologies via a bridge. Upon examination of numerous motivational theories and results, the incorporation of the Self-Determination Theory (SDT) consisting of autonomy, competence and relatedness would assist in the transition from situational interest to individual interest. This extended model was labelled as the Interest-Bridge Model. However, two of the existing elements in SDT did not cater towards older adults' requirements for learning of mobile touch screen technologies. This is, primarily because older adults have different needs and priorities when compared to children and younger adults. Additionally, Socioemotional Selectivity Theory (SST) was also incorporated into the extended model. Consequently, autonomy remained but 
competence was replaced by life-satisfaction and relatedness to self-confidence. In order to demonstrate and ascertain that the hypothesis on interest transiting from one phase to the next is achievable within a short timeframe, a Conceptual Phase was conducted to trial the teaching concepts, guidelines and tools developed.

Subsequently, for the In-Depth Study, a larger sample size assisted with the refinement of teaching concepts, guidelines (Table 7) and tools developed in the Conceptual Phase. The concept of interest-based learning has helped with the reduction of barriers faced by older adults. These barriers included a lack of knowledge, lack of assistance and lack of confidence. Across these four studies, results from each had answered the research subquestions posed within each individual study. The approach of harnessing older adults' pre-existing interests has also facilitated their learning. Thus, this research demonstrated that the Interest-Bridge Model (Figure 7) is able to represent older adults' transition of mobile touch screen technology learning from situational interest to individual interest in a classroom setting. Additionally, interest as the main driver has increased their uptake of mobile touch screen technologies.

Table 7. Guidelines developed for running of classes.

\begin{tabular}{|c|c|c|}
\hline Life-satisfaction & Autonomy & Self-confidence \\
\hline Purposes & Own devices & Handing out materials \\
\hline Goals & Decisions on curriculum & Repetitions of activities \\
\hline Pre-existing interests & Purchase advice & Self-directed use at home \\
\hline Build on life experiences & Basic tablet interactions & $\begin{array}{c}\text { Apply learnings to real-world } \\
\text { context }\end{array}$ \\
\hline
\end{tabular}

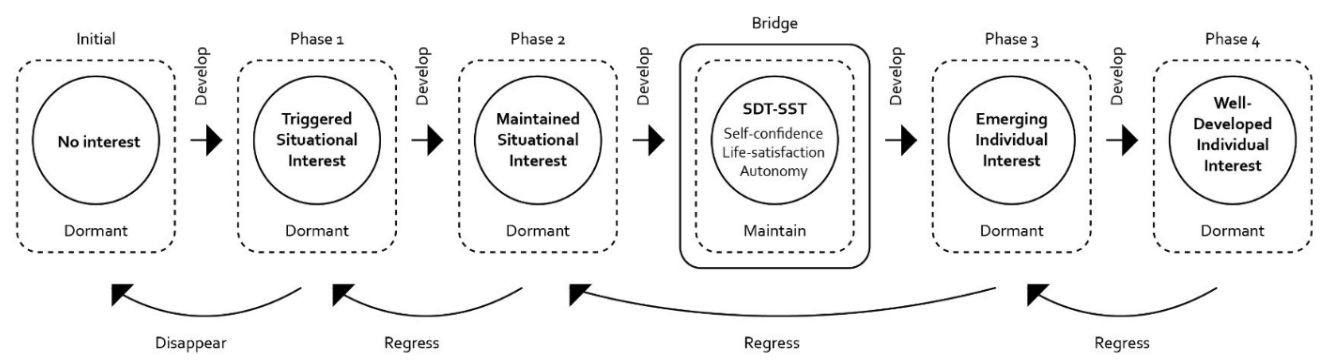

Figure 7: The Interest-Bridge Model adapted by Beh et al. (2015) and informed by Hidi and Renninger (2006), Deci and Ryan (1985) and Carstensen (1992).

\section{Conclusion}

As life expectancy continues to increase, the quality of life is not necessarily equivalent. Increased life expectancy could equate to people living in ill health for a longer period of time. However, as science and technology continue to advance, adding years to life could be achieved by the compression of morbidity, whereby ill health is concentrated on the last few years of the human lifespan. In simple terms, we are getting a longer 
timespan for our third age. So, the period of ageing is seen as an opportunity for older adults to pursue new interests to challenge themselves and learn new skills. However, the low uptake of technology amongst older adults is causing concerns with government and local organisations. Reports have shown that older adults are slower in the adoption of technology when compared to their younger counterparts. The digital gap among this cohort is widening as they get older. Even though technology claimed to support many of our daily activities and promised to make our lives easier, in fact it has not done so for everyone. Many older adults are feeling frustrated, as they are constantly trying to keep up with the emergence of new technologies and might have problems integrating technologies in useful ways in their lives, hence feeling excluded from common use.

This research has examined older adults' pre-existing interests and approaches by which it could be harnessed to support their learning and uptake of mobile touch screen technologies. This cohort has provided insights into barriers they have encountered with adoption of technology. They volunteered and persevered through learning basic tablet interactions, applying the learning in real world contexts. Their self-empowerment and engagement with their interests has widened, because of their willingness to embrace technology into their everyday lives. By applying their thirst for knowledge to learning about technology, through their pre-existing interests, they have obtained greater autonomy, self-confidence and life-satisfaction. This study set out to extend and expand on an existing interest framework of the four-phase model of interest development by Hidi and Renninger (2006) and has achieved its aims and goals with assistance from Deci and Ryan's Self-Determination Theory (1985) and Carstensen's Socioemotional Selectivity Theory (1992). The outcome was the Interest-Bridge Model, a set of guidelines and teaching concepts for running of classes with older adults. The end result presented the implementation of an interest-based curriculum as a novel learning technique for older adults to take up mobile touch screen technologies. Simultaneously, assuring that the activities designed and developed in class sessions were associated with participants' pre-existing interests that could be incorporated into their everyday lives.

In closing, the existing interest model by Hidi and Renninger (2006) catered towards children and younger adults in the school environment. This research has contributed towards the extension and expansion of the existing interest model for older adults to support their learning and uptake of technology and in this case, mobile touch screen technologies. The skills that older adults obtained through attending these classes would assist with building up their technological knowledge and self-confidence, thus, leading them towards the full use and engagement with the range of products and services that should be available to everyone regardless of their age group. 


\section{References}

Agronin, M. (2011). How we age. Cambridge, MA: Da Capo Press.

Akhtar, H., Kemao, Q., \& Kakarala, R. (2017). A review of sensing technologies for small and large-scale touch panels. Fifth International Conference on Optical and Photonics Engineering. doi: 10.1117/12.2270631.

Australian Bureau of Statistics (2017). Australian Demographic Statistics, June 2017 (3101.0). http://www.abs.gov.au/ausstats/abs@.nsf/mf/3101.0

Australian Communications and Media Authority (2016). Digital lives of older Australians. https://www.acma.gov.au/theACMA/engage-blogs/engage-blogs/Research-snapshots/ Digital-lives-of-older-Australians.

Baker, S., Waycott, J., Pedell, S., Hoang, T., \& Ozanne, E. (2016). Older people and social participation: from touch screen to virtual realities. ACM ITAP'16. doi: $10.1145 / 2996267.2996271$

Barnes, L. L., Mendes de Leon, C. F., Wilson, R. S., Bienias, J. L., \& Evans, D. A. (2004). Social resources and cognitive decline in a population of older African Americans and whites. Neurology, 63(12), 2322-2326.

Beh, J., Pedell, S., \& Doubé, W. (2015). Where is the "I" in iPad?: the role of interest in older adults' learning of mobile touch screen technologies. In $\mathrm{ACM} \mathrm{OzCHI}$ '15 Proceedings of the Annual Meeting of the Australian Special Interest Group for Computer Human Interaction, (pp. 437-445). ACM.

Beh, J., Pedell, S., \& Doubé, W. (2016). Evaluation of interest-bridge mode: older adults meditated learning of mobile technology. In ACM OzCHI '16 Proceedings of the Annual Meeting of the Australian Special Interest Group for Computer Human Interaction, pp. (pp. 293-301). ACM.

Berzin, S. C., Singer, J., \& Chan, C. (2015). Practice innovation through technology in the digital age: a grand challenge for social work. American Academy of Social Work \& Social Welfare, Grand Challenges 9: Harness Technology for Social Good, working paper no. 12 .

Betts, K. (2014). The ageing of the Australian population: triumph or disaster? http:// apo.org.au/node/39433

Black, A. E., \& Deci, E. L., (2000). The effects of instructors' autonomy support and students' autonomous motivation on learning organic chemistry: A Self-Determination Theory perspective. Science Education, 84 (6), 740-756. John Wiley \& Sons, Inc. doi: 10.1002/1098-237X(200011)84:6<740:AID-SCE4>3.0.CO;2-3

Boulton-Lewis, G. (2009). Issues in Learning and Education for the Ageing, adapted from Education and Learning for the Elderly: Why, How and Why. Educational Gerontology, 36(3), 213-228.

Caprani, N., O’Connor, N. E., \& Gurrin, C. (2012). Touch Screens for the Older User. Assistive Technologies, pp. 95-118. Retrieved from https://cdn.intechopen.com/pdfs-wm/ 31905.pdf

Carstensen, L. L. (2007). Growing old or living longer: take your pick. Issues in Science and Technology, 23(2), 41-50.

Carstensen, L. L., \& Charles, S. T. (1998). Emotion in the second half of life. Current Directions in Psychological Science, Cambridge University Press, 7(5), 144-149. 
Carstensen, L. L. (1992). "Social and Emotional Patterns in Adulthood: Support for Socioemotional Selectivity Theory". Psychology and Aging 7 (3), 331-338, doi: 10.1037/0882-7974.7.3.331

Carstensen, L. L., Isaacowitz, D. M., \& Charles, S. T. (1999). Taking time seriously. A theory of socioemotional selectivity. American Psychological Association, Inc., 54(3), 165-181.

Charles, S. T., \& Carstensen, L. L. (2009). Social and emotional aging. The Annual Review of Psychology, 61, 383-409. Retrieved from http://www.annualreviews.org/doi/pdf/ 10.1146/annurev.psych.093008.100448

Council for The Ageing and Jones, E. (2012). Older Victorians Online: A Community Survey Exploring the Usage Patterns of Older Victorians Online. Retrieved from http:// $1 \mathrm{ibrary}$. b s 1 . or g. a u/j s pu i/b i t s trea m/1/3039/1/ Older_Victorians\%20Online_COTA_Ellis_March2012.pdf.

Danial-Saad, A., \& Chiari, L. (2017). A multidisciplinary approach for developing screen devices. Disability and Rehabilitation: Assistive Technology. Taylor \& Francis Group. doi: 10.1080/17483107.2017.1370500.

Deci, E. L., \& Ryan, R. M. (1985). The General Causality Orientations Scale: SelfDetermination in Personality. Journal of Research in Personality, 19(2), 109-134.

Deci, E. L., \& Ryan, R. M. (2008). Facilitating optimal motivation and psychological wellbeing across life's domain. Canadian Psychology, 49(1), 14-23.

Deci, E. L., Olafsen, A. H., \& Ryan, R. M. (2017). Self-determination theory in work organizations: the state of a science. Annual Review of Organizational Psychology and Organizational Behavior, 4(19), 19-43.

Deckop, J. R., \& Cirka, C. C. (2000). The Risk and Reward of a Double-Edgedsword: Effects of a Merit Payprogram on Intrinsic Motivation. Nonprofit and Voluntary Sector Quarterly, 29(3), pp.400-418. doi: 10.1177/0899764000293003

Department of Economic and Social Affairs (2015). United Nations. World fertility patterns. http://www.un.org/en/development/desa/population/publications/pdf/fertility/worldfertility-patterns-2015.pdf.

Doubé, W., \& Beh, J. (2012). Typing Over AutoComplete: Cognitive Load in Website Use by Older Adults. ACM OzCHI'12 Proceedings of the Annual Meeting of the Australian Special Interest Group for Computer Human Interaction, November 26-30, Melbourne, Australia: ACM. doi: 10.1145/2414536.2414553.

Doyle, J., Skrba, Z., McDonnell, R., \& Arent, B. (2010, September). Designing a touch screen communication device to support social interaction amongst older adults. In Proceedings of the 24th bcs interaction specialist group conference (pp. 177-185). British Computer Society.

Durick, J., Robertson, T., Brereton, M., Vetere, F., \& Nansen, B. (2013, November). Dispelling ageing myths in technology design. In Proceedings of the 25th Australian ComputerHuman Interaction Conference: Augmentation, Application, Innovation, Collaboration (pp. 467-476). ACM.

Edgar, P. (2013). In Praise of Ageing. Melbourne, Australia: Text Publishing.

Glymour, M. M., Weuve, J., Fay, M. E., Glass, T., \& Berkman, L. F. (2008). Social ties and cognitive recovery after stroke: does social integration promote cognitive resilience? Neuro-epidemiology, 31, 1-20.

Hagay, G., Baram-Tsabari, A., Ametller, J., Cakmakci, G., Lopes, B., Moreira, A., \& Pedrosade-Jesus, H. (2013). The Generalizability of Students' Interests in Biology across 
Gender, Country and Religion. Res Science Education, 43, pp.895-919. doi: 10.1007/ s11165-012-9289-y

Harvey, P. W., \& Thurnwald, I. (2009). Ageing Well, Ageing Productively: The Essential Contribution of Australia's Ageing Population to the Social and Economic Prosperity of the Nation. Health Sociology Review, 18(4), 379-386.

Hidi, S., \& Renninger, K. A. (2006). The Four-Phase Model of Interest Development. Educational Psychologist, 41(2), 111-127.

Internet World Stats (2018). Internet users in the world. https://www.internetworldstats.com/ stats.htm

Kendig, H., \& Browning, C. (2011). Directions for ageing well in a healthy Australia. Dialogue (Academy of the Social Sciences in Australia), 30(2), 23.

Krapp, A. (2002). An Educational-Psychological Theory of Interest and its Relation to SelfDetermination Theory. The Handbook of Self-determination Research (pp. 405-427). Rochester, NY: University of Rochester Press.

Lindsay, S., Jackson, D., Schofield, G., \& Olivier, P. (2012, May). Engaging older people using participatory design. In Proceedings of the SIGCHI conference on human factors in computing systems (pp. 1199-1208). ACM.

Manyika, J., \& Roxburgh, C. (2011). The great transformer: The impact of the Internet on economic growth and prosperity. McKinsey Global Institute, 1.

Minges, M. (2016). OECD. Economic and social benefits of internet openness. World Development Report. Background Paper: Digital Dividends.

Morris, J. J., \& Alam, P. (2012). Value relevance and the dot-com bubble of the 1990s. The Quarterly Review of Economics and Finance, 52, 243-255.

Niemiec, C. P., \& Ryan, R. M. (2009). Autonomy, Competence and Relatedness in the Classroom: Applying Self-Determination Theory to Educational Practice. Theory and Research in Education, 7(2), 133-144. doi: 10.1177/1477878509104318

Nimrod, G. (2010). Seniors' online communities: A quantitative content analysis. The Gerontologist, 50(3), 382-392.

Noels, K. A., Pelletier, L. G., Clement, R., \& Vallerand, R. J. (2000). Why are you learning a second language? Motivational orientations and Self-Determination Theory. Journal of Research in Language Studies, 50(1), 57-85.

Organisation for Economic Co-operation and Development (2015). Ageing in Cities. http:// www.keepeek.com/Digital-Asset-Management/oecd/urban-rural-and-regionaldevelopment/ageing-in-cities_9789264231160-en\#.WoeDxYiGOUk\#page5

Östlund, B. (2005). Design Paradigms and Misunderstood Technology: The Case of Older Users. In B. Östlund (ed.), Young Technologies in Old Hands: An International View on Senior Citizens' Utilization of ICT, 25-39, Copenhagen: DJOF Publishing.

Patton, M. Q. (2015). Qualitative research and evaluation methods. 4th edition. USA: Sage Publications, Inc.

Pedell, S., Beh, J., Mozuna, K., \& Duong, S. (2013, November). Engaging older adults in activity group settings playing games on touch tablets. In Proceedings of the 25th Australian Computer-Human Interaction Conference: Augmentation, Application, Innovation, Collaboration (pp. 477-480). ACM.

Reeder, B., Zaslavksy, O., Wilamowska, K. M., Demiris, G., \& Thompson, H. J. (2011). Modeling the oldest-old: personas to design technology-based solutions for older adults. 
In AMIA Annual Symposium Proceedings Archive, 1166-1175. American Medical Informatics Association.

Reeve, J. (2005). Understanding Motivation and Emotion, 4th edition. New York: Wiley.

Renninger, K. A, \& Hidi, S. (2011). Revisiting the Conceptualization, Measurement, and Generation of Interest. Educational Psychologist, 45(3), 168-184.

Renninger, K. A., \& Su, S. (2012). Interest and Its Development. Handbook of Human Motivation, NY: Oxford University Press.

Ryan, R. M., \& Deci, E. L. (2000). Intrinsic and Extrinsic Motivations: Classic Definitions and New Directions. Contemporary Educational Psychology, (25), 54-67, doi:10.1006/ceps. 1999.1020

Sánchez-Valle, M., Abad, M. V., \& Llorente-Barroso, C. (2017). Empowering the Elderly and Promoting Active Ageing Through the Internet: The Benefit of e-inclusion Programmes. In Safe at Home with Assistive Technology (pp. 95-108). Cham: Springer.

Sander, M., Oxlund, B., Jespersen, A., Krasnik, A., Mortensen, E. L., Westendorp, R. G. J., \& Rasmussen, L. J. (2015). The challenges of human population ageing. Age and Ageing, 44(2), 185-187.

Satariano, W. A., Scharlach, A. A., \& Lindeman, D. (2014). Aging, place, and technology: toward improving access and wellness in older populations. Journal of Aging and Health, 26(8), 1373-1389. doi: 10.1177/0898264314543470

Saxon, S. V., Etten, M. J., \& Perkins, E. A. (2015). Physical change \& aging: a guide for the helping professions. 6th edition. New York: Springer Publishing Company.

Sheldon, K. M., \& Krieger, L. S. (2007). Understanding the negative effects of legal education on law students: a longitudinal test of Self-Determination Theory. The Society for Personality and Social Psychology, Inc., 33(6), 883-897. doi: 10.1177/0146167207301014

Sperry, L., \& Prosen, H. (1996). Aging in the Twenty-first Century: A Developmental Perspective. New York: Garland Publishing.

Standage, M., Duda, J. L., \& Ntoumanis, N. (2005). A test of self-determination theory in school physical education. British Journal of Educational Psychology, 75(3), 411-433.

Statistia (2018). Global Apple iPad sales from 3rd fiscal quarter of 2010 to 1st fiscal quarter of 2018 (in million units). https://www.statista.com/statistics/269915/global-apple-ipadsales-since-q3-2010/.

United Nations Conference on Trade and Development (2017). Information Economy Report: Digitalization, Trade and Development. http://unctad.org/en/PublicationsLibrary/ ier2017_en.pdf

Upton, D., Upton, P., Jones, T., Jutlia, K., \& Brookder, D. (2011). Evaluation of the Impact of Touch Screen Technology on People with Dementia and their Carers within Care Home Settings. Apps for Dementia. UK: University of Wrcester.

Waycott, J., Pedell, S., Vetere, F., Ozanne, E., Kulik, L., Gruner, A., \& Downs, J. (2012). Actively engaging older adults in the development and evaluation of tablet technology. ACM OzCHI'12 Proceedings of the Annual Meeting of the Australian Special Interest Group for Computer Human Interaction, (pp. 643-652). ACM.

Wheale, P. R., \& Amin, L. H. (2010). Bursting the dot.com "Bubble": a case study in investor behaviour. Technology Analysis \& Strategic Management, 15(1), 117-136. 
Whitbourne, S. K. (2008). Adult development \& aging: biopsychosocial perspectives. 3rd edition. Hoboken, NJ: John Wiley.

Williams, G. C., \& Deci, E. L. (1996). Internalization of biopsychosocial values by medical students: a test of Self-Determination Theory. Journal of Personality and Social Psychology, 70(4), 767-779. American Psychological Association, Inc.

Wilson, R.S., Scherr, P.A., Schneider, J.A., Tang Y., \& Bennett, D.A. (2007). Relation of cognitive activity to risk of developing Alzheimer disease. American Academy of Neurology, 69(2), 1911-1920. 